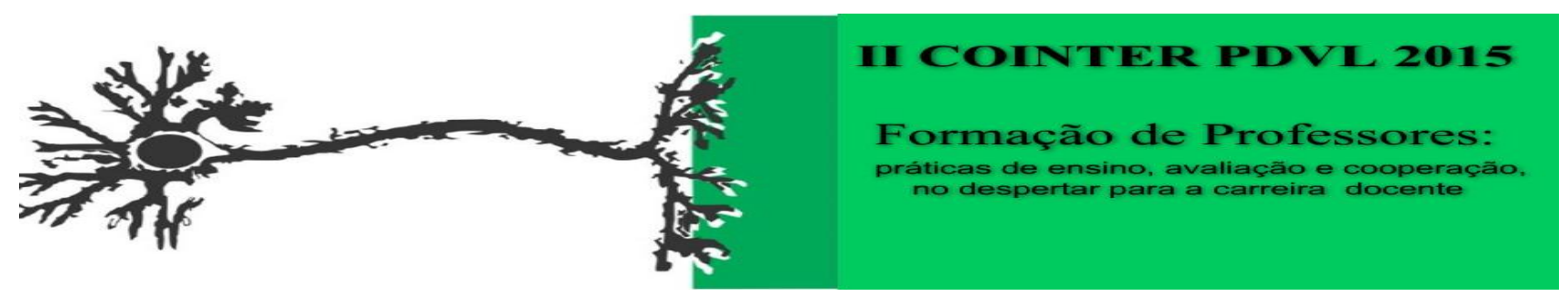

\title{
AIMPORTÂNCIA DO LÚDICO NO PROCESSO DE ENSINO-APRENDIZAGEM: A INSERÇÃO DA QUÍMICA NO ENSINO DE CIÊNCIAS
}

\author{
Apresentação: Relato de Experiência \\ Thais Soares da Silva ${ }^{1}$; Dannielle Inglydes Bezerra da Silva ${ }^{2}$; Patrícia Luana Barbosa da \\ Silva $^{3}$; Priscilla do Carmo ${ }^{4}$
}

\section{Introdução}

Nos dias atuais ainda encontramos um elevado índice de problemas relacionados ao processo de ensino aprendizado nas escolas. Isso pode se dá, em virtude do uso de estratégias tradicionais, que sobretudo são agravados na medida em que os alunos, muitas vezes, não encontram significado nas aulas que são obrigados a frequentar diariamente.

O uso de práticas diferentes como a utilização de jogos didáticos, sequências didáticas, modelos didáticos, dentre outros, inseridos na rotina dos alunos acabam os estimulando a aprender melhor o conteúdo. Portanto para melhoramos a interação aluno-professor, ensino-aprendizagem é de grande importância à utilização de metodologias dinâmicas e multidirecionais que podem resultar em momentos prazerosos durante a aula.

\section{Relato de Experiência}

O presente trabalho foi desenvolvido pelas discentes da Universidade Federal de Pernambuco- UFPE/CAV. A atividade foi desenvolvida com alunos do $9^{\circ}$ ano da escola municipal Aglaires da Silva Cruz Moura, com cerca de 35 (trinta e cinco) alunos. Inicialmente a professora da disciplina fez uma explanação do conteúdo teórico onde a temática em qustão foi os elementos químicos e posteriormente a classificação da tabela periódica, onde foi debatido como os elementos estão organizados na tabela periódica, além de suas propriedades como massa e número atômico; Ao término da explanação realizamos um quiz de perguntas e respostas como forma de avaliação onde podemos observar que os alunos não conseguiram assimilar concretamente o conteúdo. Na aula seguinte realizamos uma intervenção pedagógica, onde utilizamos o jogo didático como processo facilitador no processo de ensino aprendizagem, pois, cada pessoa é dotada de

\footnotetext{
${ }^{1}$ Licenciatura Ciências Biológicas, UFPE-CAV, thais.soares1994@gmail.com

${ }^{2}$ Licenciatura Ciências Biológicas, UFPE-CAV, danniellyinglydes@hotmail.com

${ }^{3}$ Licenciatura Ciências Biológicas, UFPE-CAV, pattricialuana@hotmail.com

${ }^{4}$ Pedagoga, Mestre em educação UFPE-CAA. priscillacarmopontes@hotmail.com
} 
competências e habilidades diferentes, portanto nem todas aprendem e detêm o conhecimento da mesma forma segundo a teoria das múltiplas inteligências de Gardner (1985). Segundo a Lei de Diretrizes e Bases da Educação Nacional No 9.394/96, (BRASIL, 1996), em seu artigo 3º, inciso I, um dos princípios do ensino é garantir a igualdade de condições para o acesso e permanência na escola. Portanto, o educador deve utilizar diferentes estratégias e os jogos didáticos surgem como alternativa viável para o aprimoramento do processo de ensino aprendizagem.

Figura1: Foto a esquerda marcação das tabelas do bingo. Foto a direita explanação e debate do conteúdo.

Fonte: Própria

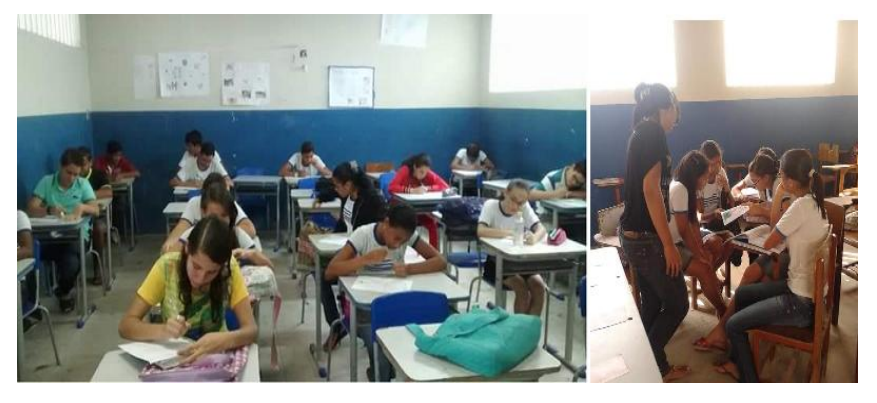

O jogo didático foi iniciado com cada aluno recebendo uma cartela contendo os elementos da tabela periódica e em seguida deu-se ínicio ao bingo, onde era selecionados aleatoriamente a sigla dos elementos químicos e os alunos tiveram que associar as siglas com o nome dos elementos, ganhando o jogo aquele aluno que conseguisse completar primeiro a tabela. Ao término da tabela podemos constatar que os alunos assimilaram melhor o conteúdo, compreendendo a realção entre os elementos químicos, suas siglas e suas propriedades. Portanto, diversificar e inovar nas práticas adotadas em sala de aula pode vir a facilitar a aquisição do conhecimento e de certa forma, faz com que o aluno se sinta estimulado a buscar novas formas de conhecimento. Por isso, um dos grandes desafios do educador é tornar o ensino prazeroso.

\section{Considerações}

Conclui-se que a utilização dos jogos didáticos favorece a aprendizagem. Pois, após a realização de todas as etapas percebemos que esse trabalho gerou um interesse significativo nos alunos, motivando o aluno a conhecer, estudar os conteúdos, o que contribui para a melhoria da qualidade do aprendizado.

\section{Referências}

BRASIL. Senado Federal. Lei de Diretrizes e Bases da Educação Nacional: nº 9394/96. Brasília: 1996.

GARDNER, H., Frames of mind: The Theory of multiple intelligences. New York: Basic Book, 1985. 